\title{
Motivational Interview as a Method of Treating People with Dual Diagnosis
}

\author{
Prof. dr Andrzej Lipczyński, PhD \\ Dr Jarostaw Kinal, PhD
}

Faculty of Sociology and History, University of Rzeszow, Poland

Doi: 10.19044/esj.2018.c3p16 URL:http://dx.doi.org/10.19044/esj.2018.c3p16

\begin{abstract}
The ideal, the spiritual and the most important element of motivational intelligence is cooperation. The idea is to focus on helping with motivational problems where the customer is not ready or willing to change or have a sense of ambivalence. It is certain that motivational intelligence is not a collection of techniques.

This involves the attitude of the therapist, who does not assume absolute authoritarian attitude and is more of a partner, and rather is to investigate the client's problems with the exclusion of the attitude of giving instruction, moralistic recommendations. It is generally about support and more about creating a friendly interpersonal atmosphere that encourages cooperation. The therapist's tone of wisdom is not acceptable, but rather the actual picture of the condition being extracted from the patient. This method is more like Socrates than university lecturer. The form of educare, mining is the most appropriate. The goal is to discover within yourself the motivation for change and its extraction. The article describes the motivational intelligence technique as a tool for social workers.
\end{abstract}

Keywords: Motivational interview, social work, disabled people, dual diagnosis

\section{Introduction}

The ideal, the spiritual and the most important element of motivational intelligence is cooperation. In principle, this method is to focus on helping with motivation problems in cases where the client is not ready or willing to change or had uczcicie ambiwalen angle. It is certain that motivational intelligence is not a collection of techniques. This involves the attitude of the therapist, who does not assume absolute authoritarian attitude and is more of a partner, and rather is to investigate the client's problems with the exclusion of the attitude of giving lectures, moralistic recommendations. It 
is generally about support and more about creating a friendly interpersonal atmosphere that encourages cooperation. The therapist's tone of wisdom is not acceptable, but rather the actual picture of the condition being extracted from the patient. This method is more like Socrates than university lecturer. Educare form, extraction is the most appropriate. The goal is to discover within yourself the motivation for change and its extraction.

Responsibility for the change that is to take place rests with the client, because only the customer can decide to change. Whereas the aim is to strengthen the internal motivation to the customer has taken limited hours Vanyamake changes arising from the conviction of a nontherapist (Rollnick, Mason, Butler 2002). No therapist and client in a wellmotivated interview give reasons for change.

Under the assumptions ChNPP therapist observes and controls its own aspirations, which hinder more than help. Many authors (Rollnick, Mason, Butler 1999) clearly distinguish motivating interview from the clinical interview.

This motivational intelligence is based on partnership. The therapist creates the atmosphere to change, not forced. In no case will the therapist be concerned about defective customer views, imposing awareness and acceptance of reality, which the client does not see, or does not agree. Neither is there any lack of knowledge or insight into the customer conditioning the change. These deficits do not catch up. On the other hand, the customer's motivation for change is assumed. Motivation is reinforced by the knowledge and views of the customer. The client's self-esteem, which is clearly motivational in his interview, assumes his ability to direct himself and his ability to make decisions. There is no reference here to what the client is supposed to do. Interview incentive is based on four basic principles of a more practical (Miller 2001). It distinguishes the rules:

- $\quad$ Express what empathy;

- $\quad$ develop divergences;

- use resistance;

- $\quad$ support self-efficacy.

Empathy is the basic feature of a motivational interview involving active listening, or acceptance. Activity is listening and understanding the feelings, views of the client without making an assessment, criticizing and blaming.This does not mean in any way unanimity or approval, but one can attest to the acceptance and understanding of the client's point of view, which the therapist does not agree or disagree with. Accept and understand the customer's point of view. Empathetic therapist tries to understand the client's feelings and views without judging, criticizing and blaming. The empathic therapist tries to accept the client's views as understood and, at least within his hierarchy of values,sadnione. Accepts ambivalence, as a normal part of human 
experience and change, he does not see as malignant pathology or defensiveness.

Motivating purpose of the interview is to encourage the client not to accept himself as he is. In case of double diagnosis, changes are recommended. The importance is how to present the customer a reality that does not belong to the pleasant. In these circumstances, the interview incentive may be modified.

Customer focused therapies, which are used in other cases, help people understand and organize their lives, or make important decisions. The motivational interview is based on a specific goal: to start the change process, assistance in the transition to the ambivalence stage and to the leading to a positive change in behavior. One of the principles of motivational interview is that you must create and deepen the gap (from the point of view of the customer) between its present and I saved his goals and values (Miller 1983), namely the creation of cognitive dissonance, using the concept introduced by Leona Festingera (1957). In this perspective, about six more easily understoodnot as a condition in the discrepancy between the current state and the desired state while avoiding the pursuit of cognitive consistency.

It may result from the current cost of awerness of hiding and dissatisfaction with it and the expected benefits of changing behavior. When a person perceives the behavior as a colloquial giving important goals (such as health, success, happiness a family or a positive selfimage), the probability of you the change is greater.

If the behavioral variation is very large, the donkey can be motivated, reducing trust. The larger the abyss, that man Age has less faith in being able to jump. Rozbieżniość in the Retention may be relatively small, but the importance of overcoming it is very high. While it is easy to imagine a gap in behavior so large that it negatively influences motivation, it is hard to imagine a change too important to implement. Just as validity and trust are different aspects of motivation, so different Race and behavior change influence motivation in many ways the way.

Many people see the meaning at the time they sign up for advice the divergence between what is happening in their lives and what they would like. At the same time, they are ambivalent; are involved in conflictavoidance. The purpose of the motivational interview is to explain Dissemination of discrepancies - use of it, gradual intensification and finally to bring such intensity that it breaks the inertia status quo. The $\mathrm{O}$ wiadzeie motivating substantially choddzi by making changes in the client is not due to okloliczności or n Ciski and external, these changes need to be internal. Intelligently motivated interview the person changes the perception (divergence) without triggering the client the impression of 
coercion or pressure. A sense of compulsion arises when one tries to change behavior because it is divergent ne of the goals or values of others.

The result of this approach is that the client himself gives reasons why he or she should change and not listen to the therapist. People often much more convinced what they say than what they hear from others.

Another pallet is the use of customer resistance. Failure to discuss, bind the arguments of the client. In the situation of emerging ambivalence should be forced to force the client to accept the therapist's argument, because in defense there appears defending. Korzsystna przypadu this strategy is not replies $~ Æ$ atau but use the force of arguments customer and rotates it so that it to your advantage. Keep in mind that the customer is not in the motivational interview to beat. The customer's resistance can be rotated or slightly reformatted to create a new impetus for change. in the interview The motive does not resist directly, but it is used to surrender to it. In general, the customer makes the final decision about what to do with the problem material. Tera Peut does not fight reluctance and ambivalence, but recognizes them as natural and understandable. Does not impose a new customer views or purposes, but it only shows the new information and offers a new look at the problem. The customer will take what he needs. With achowania client and that is called "resistance" in the interview are motivating signal for the therapist that zoom do not modify your approach a bit. Resistance is an inter phenomenon personal, and the response of the therapist decides whether it will be intensified or weakened (Miller, Rollnick 2002).

Self-efficacy is the principle on torej ope ra to wyuwiad motivating. . Samosku teczność is one of the most important elements, and gives motivation to change nadziję Frank, Frank, 1991; Miller 1985, Shapiro 1971). The client, in principle, should be convinced of the possibility of poonywania obstacles and make changes (Jones, 197 7; Leake, King, 1997; Parker, Winstead, Willi, 1979). No one can divert the customer from making a change. Interview motivating assumes no idea that the therapist change client.

Conducting in practice motivational interview is necessary to understand the basic spirit and of this method. Motivational interviews respect the autonomy of the individual and his or her right to choose. It is based on cooperation, not on giving re cept. The therapist stimulates the internal motivation of the client and activates his or her own resources to change. We assume that everyone has the motivation and the power to put in the effort and that they only need to be stimulated; You do not have to insert them. Tha task Peyton is to launch this potential and facilitate the course of natu rational change processes. This method helps the customer in the liberation from the trap of ambivalence. The interview is a significant motivating No more than a set of techniques useful for 
conducting therapy. The aim is to solve is no motivational problems inhibiting the natural process of change ny.

\section{Motivational interview in working with a patient with double diagnosis:}

Patients with dual diagnosis is a serious challenge for modern psychiatry and social services. Epidemiological studies, which were conducted in the field of the like ieństwa substance abuse by people with mental disorders is much higher than you might expect. The population of people with dual diagnosis showed a bigger problem than patients diagnosed with the same addiction or mental illness.

Research carried out in this field indicate strongly the importance of co-existence of statistically significant dual diagnosis of severe, chronic mental disorders such as schizophrenia, bipolar disease dwubi egunowe. The incidence of psychoactive substance abuse is even three times greater than in the general population of people with mental disorders. Other studies (Mueser, Bennett, 1995) associated with the use of psychoactive substances in the population of people treated for mental illness is relatively very high and reaches up to $65 \%$, and it is very disturbing. It is expected that this indicator is currently at this level or indicates slight fluctuations. People with dual diagnosis are a significant problem, as evidenced by the need for extreme intervention such as involuntary hospitalization. Substance abuse, reduce the efficacy of neuroleptic and increases the activity of the dopaminergic system exacerbating psychotic symptoms, increases the risk of side effects of drug overdoses, cognitive disorders (Bellach 1992 Lipczyński 2017) and the risk of destructive sometimes irreversible.

The abuse of psychoactive substances in combination with alcohol makes people in their mentally ill social and economic status worse off. Negative effects are associated with disease, depletion, homelessness of infectious diseases, sometimes even suicide (Mueser, Drake, Noordsy 1998).

In Poland, the treatment of people with dual diagnosis has not been synchronized to some point. In general, one disease was dealt with. There were no psychiatric outpatient clinics that could cure such patients. There were also specialists in this field of treatment. Once treatment with dual diagnosis was made, the therapy was not effective. Not only for reasons of organization and specialized personnel, but also because of the disease and the associated returns to take psychoactive drugs.

The integrated, incorporating not only doctors, nurses, psychotherapists, but also the social services system of treating patients with dual diagnosis increased the chances of effective help this type of patients. The main assumption of integrated treatment is that long-term care leads to greater improvement and stabilization of the mental status of patients with dual diagnosis. The phenomenon of dual-patient therapy is about 
focusing on current issues and changing motivations to reduce the use of psychoactive drugs in patients with abuse and total abstinence from addicts. Treatment is focused on long-term commitment of the patient to treatment and sobriety.

Customer engagement in the treatment program is much better, although there is still a high rate of discontinuation and return to the old style of functioning. Definitely the most important and first stage in the treatment of patients with dual diagnosis is hospitalization, accurate diagnosis and the establishment of a therapeutic program. Later, long-term treatment of patients by outpatient healthcare.

One of the important components of dual-therapy therapy, regardless of the stage in which the patient participates, is self-discipline and participation in motivational interview sessions (Martino 2000). From this module beginswith a partial hospitalization program of therapy (treatment in day wards). Such an interview should include feedback from completed questionnaires before being admitted to the hospital ward. He discusses with the patient's life story including an assessment of psychopathological symptoms, use and abuse of psychoactive substances including alcohol in the form of balance.

After the initial interview and during the operation the patient can determine the procedure to be followed, which will focus on the fact of what work should begin therapy. Patients with dual diagnosis have considerable deficits in many diseases and somatic nature. Motivational intervention may focus on changing many behaviors. It is important to work out the regularity of taking medication and maintain the mental state and to reduce or completely use psychoactive substances. The vast option, a complete abstinence. Motivational intervention involves staff who address a wide range of patient needs and problems and set a hierarchy of goals and behavior together.

Mental illness, regardless of its type, duration and course causes changes in the sphere of cognitive function (abstract thinking, concentration, working memory). People with schizophrenia show a number of cognitive, neurological and social deficits, particularly in the executive aspect (Bellach, DiClemente 1999)

As a consequence, the intervention strategy of necessity should be adjusted to the size of the deficits. One of the important elements in the intervention strategy is the patient's analysis and balance of losses and benefits resulting from the use of psychoactive substances. For this purpose, the patient accepts techniques and methods to facilitate behavioral control and coping with the need for psychoactive drugs. It is very helpful in this regard for every visualization. Way, the pace of work, the amount of information depends on the level of 
impairment cognitive (Lipczynski 2017). Patients for many reasons, such as those mentioned above, may have difficulties in implementing a therapeutic program. Then it is advisable to include the intervention of an individual, even if case management (case management). This strategy is effective due to the use of the local community, the removal of obstacles in a practical way, crisis management and social support. The strategy is personalized and involves participation in interview sessions that motivate other interested parties. As a result, you can expect the patient to stick to a fixed change plan.

The strategy of working with the patient based on a model of social learning, and the goal is to change behavior. Patients can participate in many open meetings if they are switching from psychoactive drugs (from alcohol to drugs) and other problems, such as lack of social skills.

Motivational interviewing does not involve the process of education (transfer of knowledge), patient, and it is a process very much like navigation. A change can take place when the patient sees and considers the reasons for changing his / her behavior. Changes in behavior and the patient are initiated decisive statements about the change that the e s sion are spoken by the patient in the presence of his therapist (Amrhein 2000).

Based on the test results presented in the English literature that the interview motivating is an effective method of involving patients with dual diagnosis and $y$ for the treatment of abstinence. Thus, there is a significant improvement in terms of both psychiatric problems as well as problems associated with the use of psychoactive substances (Drake and in.1998). This is a typical form of therapeutic intervention

Some centers in Poland have started training psychotherapists and are conducting therapy for people with dual diagnosis based on motivational interview. Several years elapsed, in order to reliably assess the effectiveness ofthe use of a motivational interview in individual therapy program.

\section{References:}

1. Amrhein, PC, Miller, WR, Yahne, CE, Palmer, M., Fulcher, L. (2000). Commit language emergent from amotivational interview predictive behavior change in drug-addicted clients. Paper presented at the International Conference of Treatment of Addictive Behaviors, Kap South Africa.

2. Bellack, AS (1992). Cognitive rehabilitation for schizophrenia: Is it possible? Is it necessary? Schizophrenia Bulletin, 18, 43-50.

3. Drake, RE, Mercer-McFadden, C., Mueser, K., McHugo, GJ, Bond, GR (1998). Review of integrated mental health and substance abuse treatment for patients with severe mental illness: A review of recent research. Schizophrenia Bulletin, 24 (4), 589-608. 
4. Festinger, L. (1957). A theory of cognitive dissonance. Stanford, CA: State ford University Press. (Ed. Pol. Festinger, L. [2007]. The theory of cognitive dissonance, the crowd. Julitta Rydlewska. Warsaw: PWN).

5. Frank, JD, Frank, JB (1991). Persuasion and healing: A comparative stusy of psychotherapy (3rd Ed.). Baltimore: Johns Hopkins University Press.

6. Jones, RA (1977). Self-fulfilling prophecies: Social, psychological and physiological effects of expectancies. Hillsdale, NJ: Erlbaum.

7. Leake, GJ, King, AS (1977). Effect of L counse or expectations on alcoholic recovery. Alcohol Health and Research World, 11 (3), 1622.

8. Lipczyński, A. (20016). Interview s mot wujacy. Presov

9. Martin, JE, Noto, VJ, Walters, ST (2000). A controlled trial of motivational feedback-based group vs. written intervention in college students: Projecy AIM-Greek collaboration. Paper presented at the International Conference of Treatment of Addictive Behaviors, Kap South Africa.

10. Miller, WR (1985). Living as if: How positive faith can change your life. Philadelphia FIA: Westminster Press.

11. Miller, WR, Baca, LM (1983). Two-year follow-up of the therapist and therapist-directed controlled drinking for drinkers. Behavior Therapy, 14, 441-448.

12. Miller, WR, C'de Baca, J. (1994). Quantum change: Toward the psychology of transformation. In T. Heatherton, J. Weinberger (ed.) Can personality change? (pp. 252-280). Washington: American Psychological Association.

13. Mueser, KT, Bennett, M., Kushner, MG (1995). Epidemiology of substance use disorders among persons with chronic mental illnesses. In: AF Lehm An, L. Dixon (ed.), Double jeopardy: Chronic mental illness and substance abuse(pp. 9-25). New York: Harwood Academic.

14. Mueser, KT, Drake, RE, Noordsy, DL (1998). Integrated mental health and substance abuse treatment for severe psychiatric disorders. Journal of Practical Psychiatry and Behavioral Health, 4 (3), 129-139.

15. Parker, MW, Winstead, DK, Willi, FJP (1979). Patient autonomy in alcohol rehabilitation: I. Literature review. International Journal of the Addictions, 14, 1015-1022.

16. Rollnick, S., Kinnersley, P., Butler, CC (2002). Context-bound communication skills training: Development of a new method. Medical Education, 36, 377-383. 
17. Rollnick, S., Mason, P., Butler, C. (1999). Health behavior change: A guide for practitioners. London: Churchill Livingstone.

18. Shapiro, AK (1971). Placebo effects in medicine, psychotherapy, and c hoanalysis dogs. In AE Bergin, SL Garfield (Eds.), Handbook of Psychother paws and behavior change: An empirical analysis (pp. 439-473). New York: Wiley. 